\title{
Extracción de Quitina a partir de Pluma de Calamar (loligo spp.) por un método ecológico mediante la aplicación de aceite vegetal saponificado
}

\author{
GRETA ESTÉVEZ DÁVILA', RONNY FLORES', FERNANDO NOVILLO', \\ Facultad de Ciencias Químicas, Universidad Central del Ecuador, Quito \\ * Correspondencia: fernovillo@yahoo.com
}

Recibido: 25 de abril de 2012 / Aceptado: 15 octubre de 2013

\section{Resumen}

La quitina es un polímero natural biodegradable y versátil, con un amplio campo de aplicaciones. El desecho de cefalópodos, en particular de la pluma del calamar (Loligo spp.), constituye una fuente importante de quitina. En este trabajo de investigación se aplica una metodología ecológica para aislar la quitina de los desechos del calamar. Esto se consiguió al tratar el material de desecho con un aceite vegetal saponificado al $4 \%(\mathrm{p} / \mathrm{v})$. La desproteinización de la harina de pluma del calamar se logró al reflujar durante de 2 horas. Posteriormente al tratar con $30 \mathrm{~mL}$ de una solución de $\mathrm{CaCl}_{2} \cdot 2 \mathrm{H}_{2} \mathrm{O}$ saturada en metanol y durante 5 horas de agitación se consiguió la disolución de la quitina. Durante este tratamiento se obtuvieron películas de quitina, en las cuales se demostró que la degradabilidad e intemperismo afectaron más este polímero natural que a uno de origen sintético.

Palabras clave: Quitina, pluma de calamar, aceite vegetal saponificado, solución cloruro de calcio en metanol, biodegradabilidad, intemperismo.

\section{Extraction of chitin from squid pen (loligo spp.) for an ecological approach through the application of saponified vegetable oil}

\begin{abstract}
Chitin is a naturally biodegradable polymer and versatile with a wide field of applications. Disposal of cephalopods, especially squid pen (Loligo spp.), a major source of chitin. In this research applies ecological methodology for isolating chitin from squid wastes. This was achieved by treating the waste material with a vegetable oil saponified to $4 \%(\mathrm{w} / \mathrm{v})$. The deproteinization of squid pen flour was achieved by refluxing for 2 hours. Subsequently to treat with $30 \mathrm{~mL}$ of a saturated solution in methanol and $\mathrm{CaCl}_{2} \cdot 2 \mathrm{H}_{2} \mathrm{O}$ for 5 hours of stirring the solution was achieved chitin. During this treatment chitin films were obtained, in which it was demonstrated that the degradability and weathering affected over this one natural polymer of synthetic origin.
\end{abstract}

Keywords: Chitin, squid pen, vegetable oil saponified, solution of calcium chloride in methanol, biodegradability, weathering.

\section{Introducción}

La pesca de cefalópodos, especialmente de calamares, ha sido de interés mundial durante los dos últimos decenios, pero la industrialización y comercialización de estos generan actualmente una gran cantidad de residuos, que suponen a nivel mundial, un grave problema medioambiental, ya que estos permanecen en los suelos durante largos tiempos y representan problemas de contaminación y de salud en las zonas aledañas a los vertederos en los que se depositan. Una forma de eliminar los desechos de la producción del calamar (pluma de calamar) es por incineración del material; sin embargo, estos desechos pueden ser aprovechados como materia prima para la obtención de productos de interés comercial y de investigación [1]. 
La quitina se encuentra distribuida ampliamente en la naturaleza y después de la celulosa (materia base del papel), es el segundo polímero más abundante en el planeta. Sus fuentes principales son el exoesqueleto (caparazón) de muchos crustáceos, moluscos, alas de insectos (escarabajos, cucarachas), paredes celulares de hongos, algas, etc. Estructuralmente la quitina se encuentra formada por cadenas no ramificadas de enlaces glicosídicos $\beta(1-4)$ con unidades 2-acetoamido-2-desoxi-D-glucosa-(N-acetil, D-glucosamina). El quitosano es el principal derivado desacetilado de la quitina, es un compuesto que confiere potenciales aplicaciones en diversos campos de investigación [2].

Generalmente, la quitina se extrae de los crustáceos por medio de un tratamiento básico para eliminar proteínas, seguido un ataque ácido para disolver las sales minerales [3].

La quitina es altamente hidrofóbica, insoluble en agua, en ácidos y álcalis diluidos y en la mayoría de solventes orgánicos. Posee grupos acetamida e hidroxilo con fuertes enlaces de hidrógeno que la hacen difícilmente soluble. Flores et al [4] propusieron un disolvente para quitina elaborado a base de una solución de cloruro de calcio en metanol, con el que pueden formarse películas de quitina, que facilita su uso.

En función del organismo considerado y también del papel que desempeña, la quitina adopta diferentes formas denominadas $\alpha, \beta$, y $\gamma$-quitina. La $\alpha$-quitina se encuentra en estructuras rígidas y resistentes, como en la cutícula de artrópodos y está fuertemente asociada con proteínas y materiales inorgánicos. Las formas $\beta$ y $\gamma$-quitina se producen en estructuras flexibles pero resistentes y no están asociadas a sales inorgánicas. En el género loligo la $\alpha$-quitina constituye una fina capa que reviste las paredes del esófago y el estómago, la $\beta$-quitina se presenta como el principal componente de los gladios o plumas y la $\gamma$-quitina integra una espesa capa que recubre otras zonas del estómago.

En el presente trabajo se extrae quitina de la pluma de calamar, sin necesidad de desproteinización alcalina, con la que se obtienen películas utilizando un disolvente hecho a base de una solución de cloruro de calcio en metanol.

\section{Parte experimental}

La siguiente metodología sigue el procedimiento desarrollado por Flores [5] para la extracción de quitina del cefalotórax de camarón. Plumas de calamar (Loligo spp.) secadas al sol fueron convertidas en harina (tamaño de partícula menor a $0.15 \mu \mathrm{m}$ ) para facilitar la extracción de quitina. Seguidamente, se procedió a desproteinizar la harina de pluma de calamar, con la utilización de aceite vegetal de maíz saponificado como solución digestora a diferentes concentraciones, y calor mediante diferentes tiempos de reflujo abierto. La preparación de la solución digestora se realizó pesando $44 \mathrm{~g}$ de aceite vegetal de maíz en un balón de destilación de $500 \mathrm{~mL}$. Aparte se disolvieron $6 \mathrm{~g}$ de $\mathrm{NaOH}$ en $250 \mathrm{~mL}$ de agua. Se trasvasó la solución de $\mathrm{NaOH}$ al balón con el aceite y se realizó un reflujo durante dos horas. Se aforó a $1000 \mathrm{~mL}$ con agua destilada para preparar la solución madre al $5 \%(p / v)$. Se reflujó $0.5 \mathrm{~g}$ de harina de pluma de calamar con 10 $\mathrm{mL}$ de la solución digestora de aceite saponificado a diferentes concentraciones $(1,2,3,4$ y $5 \%)$ y tiempos (1, 2, 3, 4 y 5 horas). Se filtró el producto obtenido y se desecó en una estufa a $100^{\circ} \mathrm{C}$ durante 2 horas, se pesó y calculó el porcentaje de pérdida de peso con respecto a la muestra original, que corresponde al grado de desproteinización.

Posteriormente, se procedió a la disolución de la quitina, con la aplicación de una solución de $\mathrm{CaCl}_{2} \cdot 2 \mathrm{H}_{2} \mathrm{O}$ saturada en metanol, como disolvente, y distintas horas de agitación. La preparación de este disolvente se realizó reflujando durante una hora un mol de cloruro de calcio, un mol de metanol y dos moles de agua. Se disolvió $0.4 \mathrm{~g}$ de quitina desproteinizada en diferentes volúmenes de disolvente $(20,25$ y $30 \mathrm{~mL})$ y tiempos de agitación (1, 2, 3, 4 y 5 horas). Se controló la cantidad de quitina presente en la solución, mediante medidas viscosimétricas, en un viscosímetro BROOKFIELD RVDV-II+Pro. Para que precipite la quitina se vertió agua en la solución y se agitó en un agitador mecánico. Se filtró el precipitado y se lo lavó con agua destilada. Se secó la quitina obtenida a $100^{\circ} \mathrm{C}$ durante dos horas y se procedió a pesar. Se calculó el porcentaje de quitina en la solución.

Una vez optimizadas las condiciones de extracción de la quitina, se procedió a la formación de las películas del polímero a partir de la quitina en solución, em- 
pleando dos técnicas. Se precipitó la quitina con agua y se filtró, una vez seca la película puede desprenderse de la superficie del filtro de nitrocelulosa con facilidad. Otra película se realizó en un vidrio reloj dejando secar a la intemperie la solución de quitina durante varios días. Se caracterizó a las películas obtenidas mediante un análisis de espectroscopia infrarroja.

A las películas de quitina formadas se les realizó un estudio de Degradabilidad e Intemperismo, comparándolas con láminas de poliestireno como plástico de origen sintético, durante un tiempo aproximado de 4 semanas. El estudio de Degradabilidad consistió en enterrar, a cinco $\mathrm{cm}$ de profundidad, a las películas tanto de quitina como de poliestireno en una composta de tipo doméstico y mediante evidencia fotográfica analizar el comportamiento de las láminas cada semana. Finalmente, se determinó la pérdida de peso de las láminas de los polímeros. Mientras que en el estudio de Intemperismo, las películas de quitina y poliestireno se colocaron en una plancha de espuma de poliestireno, en una posición horizontal, y se les dejó al aire libre expuestas a todos los cambios climáticos, la pérdida de peso se determinó una vez por semana [6].

\section{Resultados y discusión}

\section{Desproteinización de la harina de pluma de calamar}

Se preparó la solución digestora de aceite vegetal saponificado (SAP) a diferentes concentraciones a partir de la solución madre del $5 \%(\mathrm{p} / \mathrm{v})$ con agua destilada. Posteriormente, se tomó $10 \mathrm{~mL}$ de cada una de las concentraciones y se procedió a realizar el reflujo abierto con $0.5 \mathrm{~g}$ de harina de pluma de calamar. Se determinó que las mejores condiciones se presentaron a las dos horas de reflujo abierto y con el $4 \%(p / v)$ de SAP. En la Figura 1 se detallan los valores de porcentaje de desproteinización obtenidos para cada una de las concentraciones y tiempos de reflujo. El cálculo se realizó considerando que la pluma de calamar tiene un $32.75 \%$ de proteínas [7].

El análisis estadístico utilizado fue ADEVA, se trabajó con tres réplicas para cada proceso, se determinó que sí hay diferencia en la utilización del surfactante. A mayor concentración de este la desproteinización es mejor. El tiempo de extracción, también, ayuda en la desproteinización. En la Tabla 1 se muestran los resultados obtenidos para el análisis de varianza.

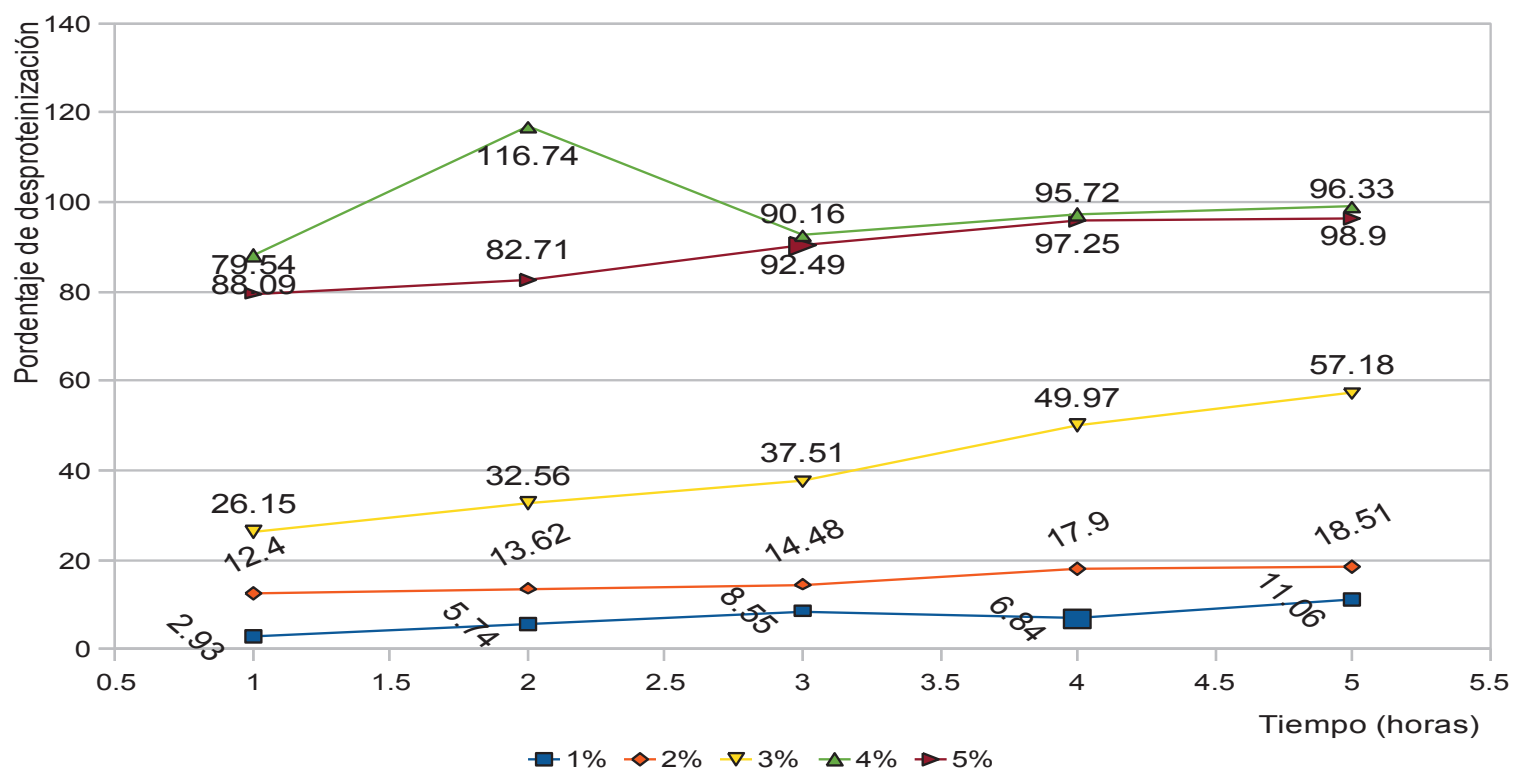

Figura 1. Relación de porcentaje de desproteinización en función al tiempo de reflujo abierto a las diferentes concentraciones de aceite vegetal saponificado. 
Tabla 1. Cuadro de resultados de ADEVA.

Desproteinización de harina de pluma de calamar

\begin{tabular}{cccccc}
\hline Fuente de variación & $\begin{array}{c}\text { Grados } \\
\text { libertad }\end{array}$ & $\begin{array}{c}\text { Suma de } \\
\text { cuadrados }\end{array}$ & $\begin{array}{c}\text { Cuadrado } \\
\text { medio }\end{array}$ & $\begin{array}{c}\mathbf{F} \\
\text { calculada }\end{array}$ & $\begin{array}{c}\mathbf{F} \\
\text { tabulada (95\%) }\end{array}$ \\
\hline $\begin{array}{c}\text { Concentración de aceite vegetal } \\
\text { saponificado }\end{array}$ & 4 & 0.02 & 0.00561384 & 84.3240 & 2.55 \\
Tiempo a reflujo abierto (h) & 4 & 0.33620407 & 0.08405102 & 1262.5834 & 2.55 \\
Interacción & 16 & 0.02529587 & 0.00158099 & 23.7491 & 1.85 \\
error & 50 & 0.00332853 & 0.00066570 & & \\
Total & 74 & 0.39 & & & \\
\hline
\end{tabular}

\section{Disolución de la Quitina}

La disolución de la quitina se determinó mediante medidas viscosimétricas en el equipo Brookfield en unidades de Centipoise (cP) a temperatura de $25^{\circ} \mathrm{C}$. Las me- jores condiciones, mayor viscosidad, se alcanzaron a las 5 horas de agitación con $30 \mathrm{~mL}$ de disolvente. En la Figura 2 se muestran los datos obtenidos para los diferentes volúmenes de disolvente y los distintos tiempos de agitación.

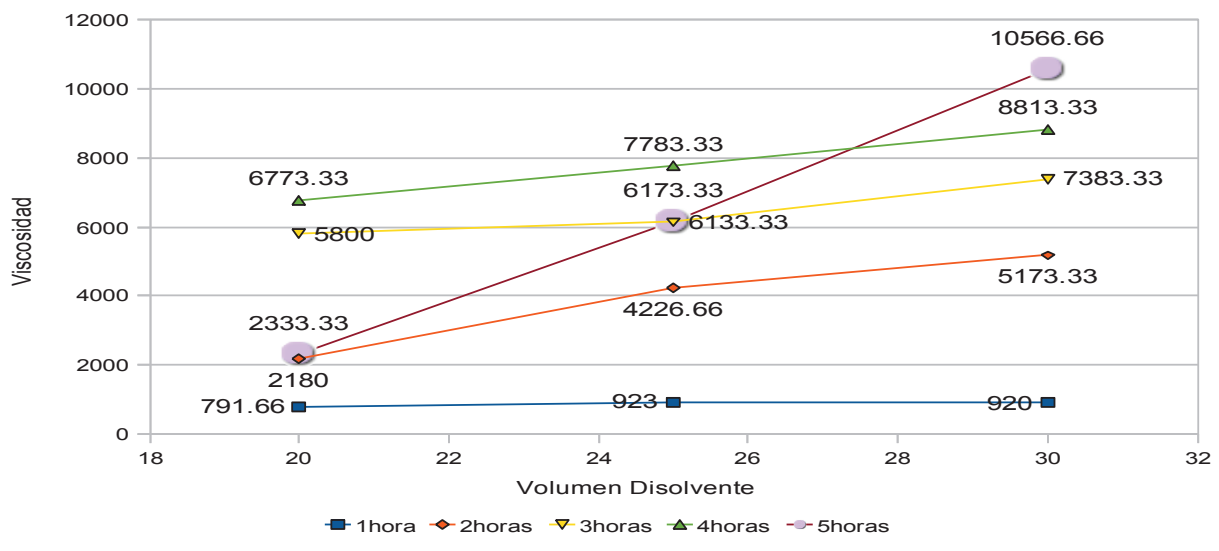

Figura 2. Relación de viscosidad, $c P$, en función al volumen de disolvente, $\mathrm{mL}$, a los diferentes tiempos de extracción, $h$.

El análisis estadístico realizado fue el análisis de varianza ADEVA con tres réplicas para cada condición (ver Tabla 2). Se estableció que hay una gran diferencia en la disolución de quitina con el aumento del volumen del disolvente. Por lo tanto, es necesario incrementar la can- tidad de éste para así lograr extraer más quitina. Lo mismo sucede con el tiempo de agitación, se confirmó que mayor tiempo de contacto del disolvente con la quitina mayor cantidad de quitina logra disolverse. Mayor disolución del biopolímero, mayor viscosidad del medio.

Tabla.2. Cuadro de resultados de ADEVA. Disolución de Quitina.

\begin{tabular}{cccccc}
\hline Fuente de variación & $\begin{array}{c}\text { Grados } \\
\text { libertad }\end{array}$ & Suma de cuadrados & $\begin{array}{c}\text { Cuadrado } \\
\text { medio }\end{array}$ & F calculada & $\begin{array}{c}\text { F tabulada } \\
\mathbf{( 9 5 \% )}\end{array}$ \\
\hline Disolvente $(\mathrm{ml})$ & 2 & 67311677.38 & 33655838.69 & 1282.87 & 3.32 \\
$\begin{array}{c}\text { Tiempo de extracción } \\
\text { (h) }\end{array}$ & 4 & 269690428.98 & 67422607.24 & 2569.98 & 2.69 \\
Interacción & 8 & 59025027.29 & 7378128.41 & 281.24 & 2.27 \\
error & 30 & 784041.33 & 26234.71 & & \\
Total & 44 & 396814174.98 & & & \\
\hline
\end{tabular}




\section{Formación de las películas de quitina}

La película de quitina se obtuvo probando dos técnicas. En un vidrio reloj se dejó secar la solución de quitina a la intemperie, con lavados sucesivos con agua destilada. Por otro lado, se empleó un filtro de membrana polimérica (nitrocelulosa) para filtrar la quitina precipitada. Esta fue la técnica más rápida y la película se desprendió con facilidad. En las Figuras 3 y 4 se muestran las dos formas de obtención de las películas de quitina.

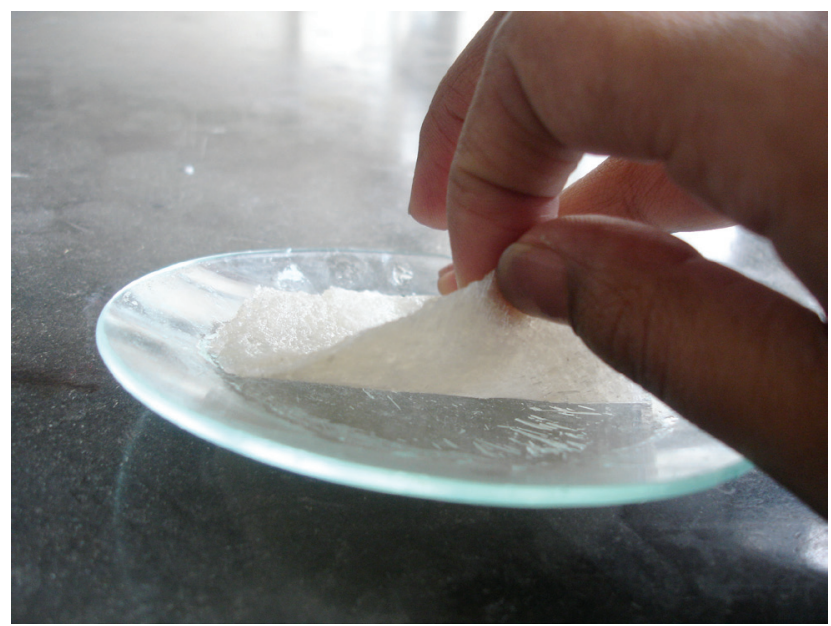

Figura 3. Formación de películas de quitina en vidrio reloj.

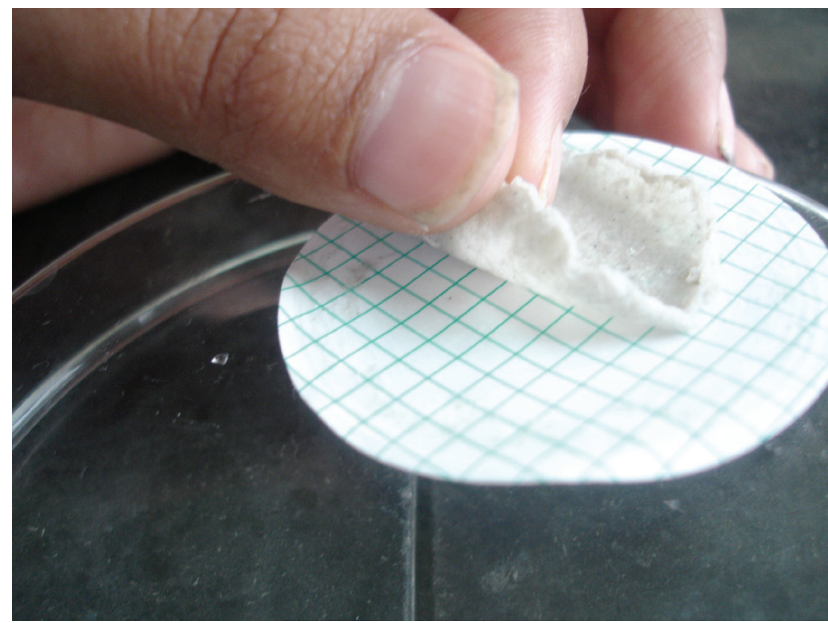

Figura 4. Formación de películas de quitina en membrana polimérica

\section{Caracterización de la película de quitina}

Se realizó un análisis espectroscópico de infrarrojo, para lo cual se obtuvo primero un espectro IR de una muestra de quitina comercial y segundo el espectro IR del producto extraído, bajo las condiciones de 2 horas de reflujo abierto y al $4 \%$ de aceite vegetal saponificado a partir de la pluma de calamar. En las Figuras 5 y 6 se muestran los espectros obtenidos para cada una de las muestras. La comparación de los picos de los dos espectros confirma que el producto obtenido en la investigación corresponde a quitina.

Se realizó un análisis de porcentaje de grado de acetilación (DA) de la muestra obtenida mediante la técnica de espectroscopia infrarroja [8]. Para esto se mezcló la muestra pulverizada de quitina con $\mathrm{KBr}$ en un mortero de ágata y se procedió a realizar las pastillas en una prensa, estas deben ser lo más transparente posibles, es decir, que el espesor debe ser minino, entre unos $0.25 \mathrm{~mm}$. Seguidamente, se correlacionaron las intensidades de las absorbancias medidas entre dos picos formados por la banda de la amida III a $1320 \mathrm{~cm}^{-1}$ y la banda de los grupos metilos a $1420 \mathrm{~cm}^{-1}$, que sirve de referencia interna para corregir las diferencias de grosor o de concentración en las pastillas de $\mathrm{KBr}$. Este cálculo se hace de acuerdo a la Ecuación 1[8]:

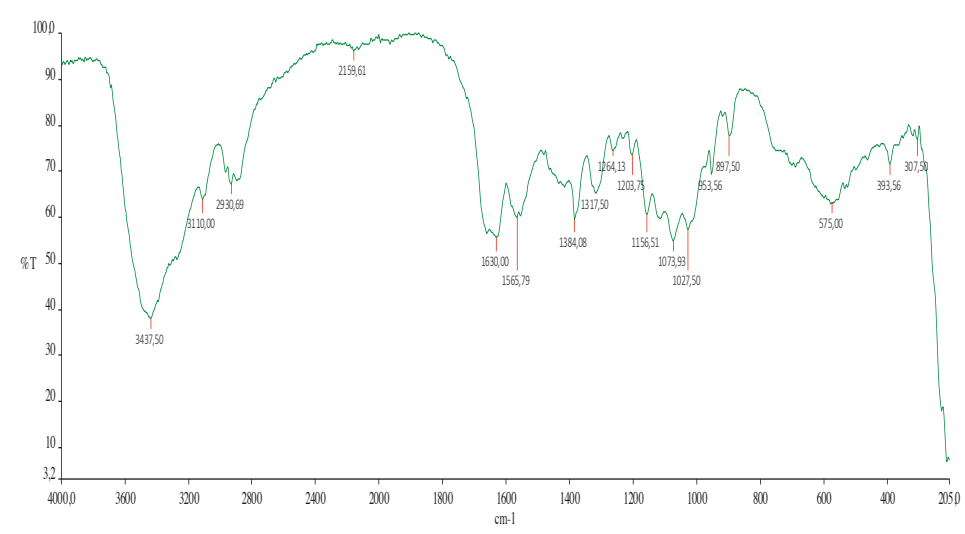

Figura 5. Espectro de Infrarrojo para muestra de quitina comercial

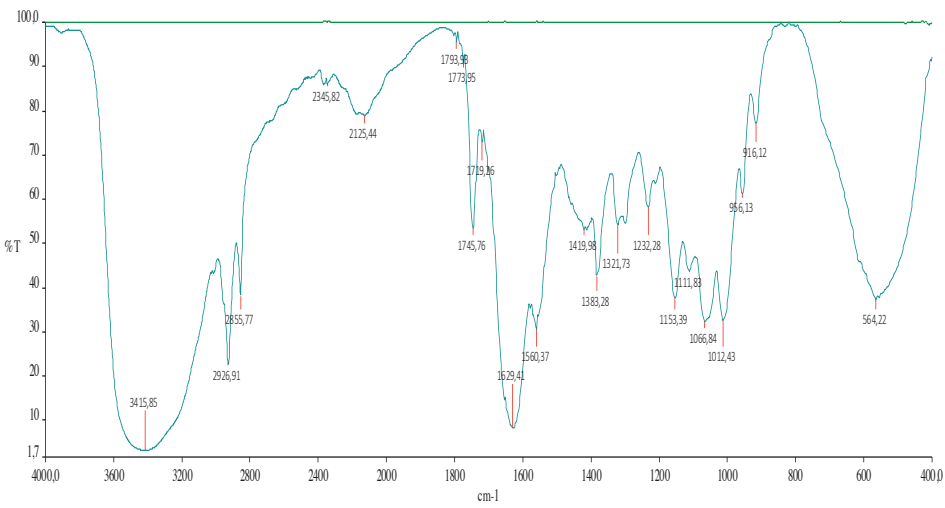

Figura 6. Espectro de Infrarrojo para muestra de quitina de pluma de calamar. 
$D A(\%)=31,92 \times\left(A_{1320} / A_{1420}\right)-12,20$

\section{Ecuación 1. Estudio de Degradabilidad e Intemperismo}

con un coeficiente de correlación $r=0.990$, donde $A$ es la absorbancia absoluta a las frecuencias correspondientes (ver Tabla 3).

Tabla 3. Porcentaje de grado de acetilación por método infrarrojo.

\begin{tabular}{ccc}
\hline & Quitina Comercial & $\begin{array}{c}\text { Quitina de pluma } \\
\text { de calamar }\end{array}$ \\
\hline \%DA1 & 81.464 & 91.111 \\
\%DA2 & 71.506 & 94.385 \\
\%DA medio & 76.485 & 92.748 \\
\hline
\end{tabular}

Los resultados en los cálculos indican que el producto obtenido por el método propuesto es quitina, ya que los valores de porcentaje de grado de acetilación son cercanos al 100\%, lo que demuestra las bondades de este procedimiento a diferencia de una hidrólisis alcalina.
Se deseaba conocer la estabilidad de las películas de quitina elaboradas comparada con una película de poliestireno por lo que se realizaron pruebas de degradabilidad e intemperismo.

\section{Estudio de Degradabilidad}

La composta utilizada para este estudio fue un suelo de humus $(40 \%$ de humedad), el recipiente en el que se colocó el suelo se tapó con papel aluminio y se dejó en una terraza, evitando que no le afecte la lluvia y la luz solar. Las películas fueron desenterradas una vez por semana y fotografiadas para evidenciar el comportamiento de estas en esas condiciones. Al término del estudio la película de quitina desapareció casi en su totalidad (Fig. 8). El porcentaje de degradación de la película de quitina fue del $71.73 \%$, mientras que el de la película de poliestireno solo fue del $0.06 \%$.

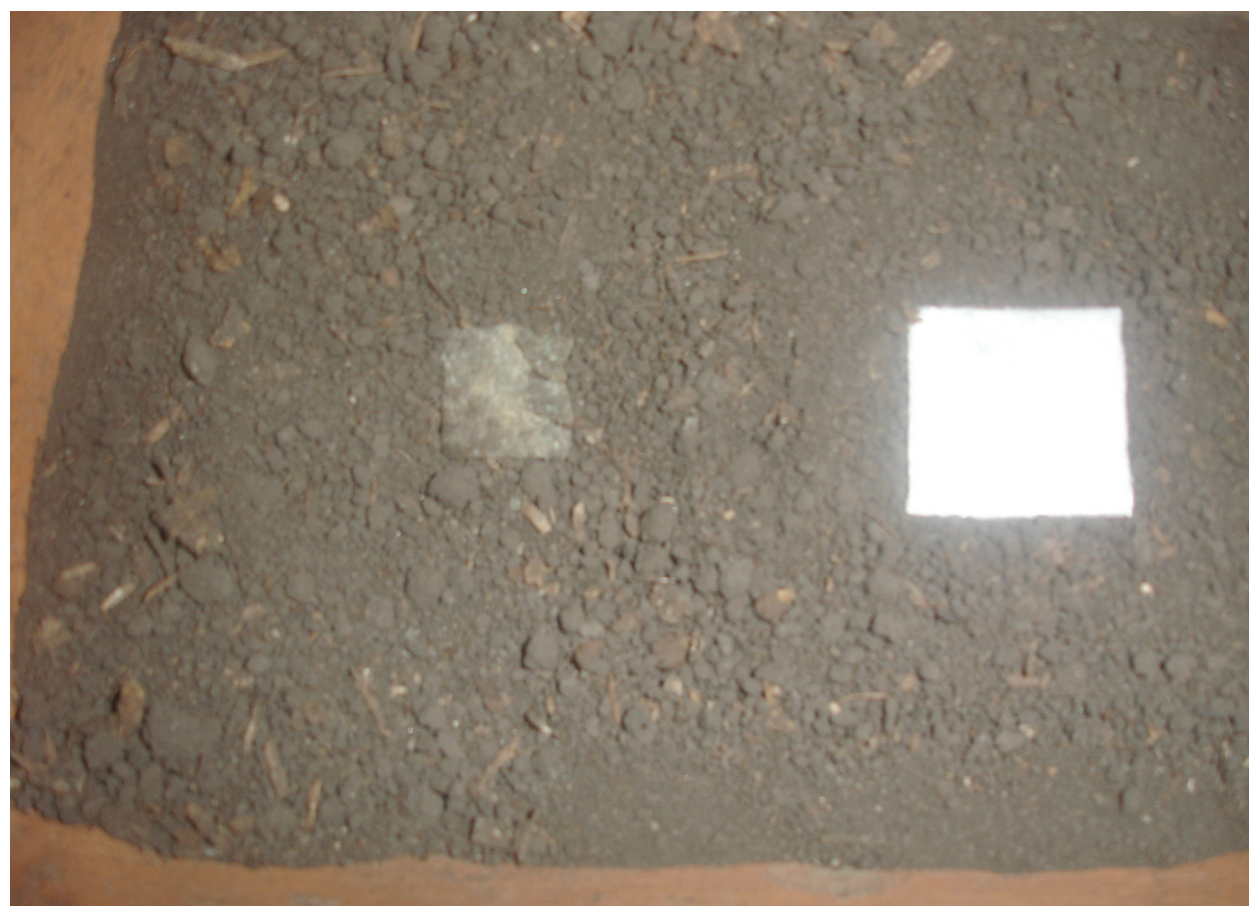

Figura 8. Tercera semana de degradación en suelo de humus. La lámina de la izquierda corresponde a la película de quitina, mientras que la lámina de la derecha corresponde a película de poliestireno. 


\section{Estudio de Intemperismo}

La lámina de quitina a la intemperie, luego de cuatro semanas, perdió un $55.2 \%$ de peso, en cambio la película de poliestireno $0.17 \%$. Con esto se concluye que, las películas de quitina a la intemperie se degradan en un tiempo más largo que en el caso anterior, probablemente porque en el suelo de humus hay microorganismos que degradan la quitina. Para la película de poliestireno sucede lo contrario, ésta se degrada un poco más rápido a la intemperie que en el suelo de humos, pero los cambios que sufre son mínimos en los dos casos.

\section{Determinación del rendimiento del proceso de extracción de quitina}

El rendimiento del método de extracción se calculó pesando la cantidad de quitina obtenida en cada paso del proceso. Se llegó a obtener $13 \mathrm{~g}$ de quitina por cada $100 \mathrm{~g}$ de harina de pluma de calamar.

\section{Conclusiones}

- Mediante la utilización de residuos producidos por el calamar y de aceite vegetal saponificado, se logró extraer quitina sin necesidad de un tratamiento alcalino.
- Con el disolvente, que fue la solución de cloruro de calcio saturada en metanol, se logró la disolución y extracción de la quitina. Es una manera más provechosa de utilizar los reactivos químicos, debido a que los componentes de esta solución pueden ser fácilmente recuperados.

- En el estudio de degradabilidad, la película de quitina presentó cambios en el tamaño y forma, dando como resultado un $71.3 \%$ de degradabilidad, mientras que, la película de poliestireno casi no presentó cambio alguno durante las semanas de estudio, demostrando así que la quitina aislada, es de fácil y de mayor degradabilidad en comparación a la película del polímero sintético.

- En la prueba de intemperismo, los factores ambientales ocurridos durante el ensayo sí afectaron las características originales de la película de quitina, mientras que para la película de poliestireno los cambios fueron mínimos.

\section{Agradecimientos}

El primer autor desea expresar su agradecimiento al Centro de Química de la Universidad Central del Ecuador por las facilidades prestadas para la realización de esta investigación.

\section{Referencias}

[1] Caprile, M. (2005) Obtención y Utilización de Quitina y Quitosano a partir de desechos de crustáceos. En libro de resúmenes del Congreso Mundial ISWA 2005: "Hacia un sistema integral de residuos sólidos urbanos". Centro de exposiciones de la rural, Buenos Aires, noviembre 2005.

[2] Ravi Kumar, M.N.V. (2000). A review of chitin and chitosan applications. Reactive \& Functional Polymers, 46, 1-27.

[3] Percot, A., Viton, Ch., Domard, A. (2003). Optimization of chitin extraction from shrimp shells. Biomacromolecules, 4, 12-18.

[4] Flores, R., Barrera, S., Durán, C. (2009). Extracción ecológica de quitina y subproductos. TíTULO DE PATENTE NO. 264482 IMPI. México.

[5] Flores, R. (2004). Bioplástico de Quitina. Formación de películas de quitina a partir de desechos de camarón por métodos ecológicos, Programa de Maestría y Doctorado en Ciencias Químicas, Universidad Nacional Autónoma de México, México DF.

[6] ASTM. (1991). ASTM D 1435-85 Standard practice for outdoor weathering of plastics. Annual Book of ASTM Standards. Vol. 08.01 Plastics, Filadelfia.

[7] Peniche, C. (2006). Estudios sobre Quitina y Quitosano, Tesis Doctoral Universidad de La Habana, Cuba.

[8] Brugnerotto, J., Lizardi, J., Goycoolea, F. M., Argüelles-Monal, W., Desbrières, J., Rinaudo, M. (2001). An infrared investigation in relation with chitin and chitosan characterization. Polymer, 42, 3569-3580. 